\title{
A Visible-NIR Responsive Dye-Sensitized Solar Cell Based on Diatom Frustules and Cosensitization of Photopigments from Diatom and Purple Bacteria
}

\author{
Xixiang Xiao, ${ }^{1}$ Xiaobo Zhang, ${ }^{1}$ Haiyang Su, ${ }^{1}$ Shicheng Chen, ${ }^{2}$ Zhihui He, ${ }^{3}$ \\ Chungui Zhao $\mathbb{D}^{1}{ }^{1}$ and Suping Yang $\mathbb{D}^{1}$ \\ ${ }^{1}$ College of Chemical Engineering, Huaqiao University, Xiamen 361021, China \\ ${ }^{2}$ Department of Microbiology and Molecular Genetics, Michigan State University, East Lansing, Michigan 48863, USA \\ ${ }^{3}$ Hunan Changsha National Biological Industrial Base, Changsha 410331, China
}

Correspondence should be addressed to Chungui Zhao; chungui@hqu.edu.cn and Suping Yang; 360825422@qq.com

Received 21 January 2020; Revised 1 March 2020; Accepted 4 March 2020; Published 24 April 2020

Academic Editor: Nenad Ignjatović

Copyright (c) 2020 Xixiang Xiao et al. This is an open access article distributed under the Creative Commons Attribution License, which permits unrestricted use, distribution, and reproduction in any medium, provided the original work is properly cited.

Diatoms exhibit high solar energy harvesting efficiency due to their remarkably organized, hierarchical micro/nanoporous, lighttrapping, and scattering frustules. At present, few studies focus on cosensitization of natural near-infrared dye to expand the spectral response of dye-sensitized solar cells. In this study, the diatom frustule- $\mathrm{TiO}_{2}(12: 5)$ composite film was prepared and assembled it on the $\mathrm{TiO}_{2}$ electrode. Compared to the single $\mathrm{TiO}_{2}$ layer film, diatom frustule- $\mathrm{TiO}_{2}(12: 5)$ composite film sensitized by diatom's dye showed the conversion efficiency of $0.719 \%$. To expand the light-harvesting response to near-infrared region spectra, the cosensitized dyes were used to fabricate the visible-near-infrared responsive dye-sensitized solar cells. The cosensitization diatom frustule- $\mathrm{TiO}_{2}(12: 5)$ composite film exhibited two distinct absorption bands in the near-infrared region and reached a higher conversion efficiency of $1.321 \%$, which was approximately 1.4 or 1.7 folds higher than that of cosensitization double- $\mathrm{TiO}_{2}$ film or single $\mathrm{TiO}_{2}$ layer film, respectively, and approximately 3.7 or 1.7 folds higher than that of the single $\mathrm{TiO}_{2}$ layer film sensitized by diatom dye or purple bacterial dye, respectively. The results showed that the combination between diatom frustule- $\mathrm{TiO}_{2}$ with cosensitization natural dyes could significantly improve the photoelectric performance of visible-near-infrared responsive dye-sensitized solar cells.

\section{Introduction}

Dye-sensitized solar cells (DSSC) have attracted considerable attention due to their ease of fabrication, low production costs, and architectural and environmental compatibility compared to silicon-based solar cells [1-4]. Currently, the dyes used in DSSC mainly fous on synthetic dyes and some plant natural dyes. Synthetic dyes such as N719 and N3 ruthenium are capable of yielding higher conversion efficiencies [5-7]. However, their fabrication is complicated, and some are toxic [8]. Natural dyes are abundant, easily available, cost-effective, and eco-friendly $[9,10]$; however, the conversion efficiency of DSSC was yet to be improved. In general, a challenge in DSSC is the expansion of absorbance range of photoactive layers. To the best of our knowledge, up to $50 \%$ of solar spectra are larger than $700 \mathrm{~nm}$, which are located in the range of the infrared radiation [11]; however, the absorption maxima in most of the synthetic or natural dyes in DSSC are within $700 \mathrm{~nm}$ [10], and their conversion efficiency in the available DSSCs may be compromised due to limited sunlight absorption of dyes. Therefore, more interests are focused on exploring the nearinfrared absorbance dyes or spectral complementary cosensitization dyes, such as synthesized FT89 NIR dye enhanced photocurrent conversion efficiency by $6 \%$ compared to N749 benchmark [12]; bacteriochlorophyll $c(\mathrm{BChl} c)$ from green sulfur bacterium showed a photocurrent conversion efficiency of $0.1 \%$ at $600-800 \mathrm{~nm}$ [13]. Cosensitizers 
(N719, black dye, SQ1, NI5, and porphyrin) could enhance the photoelectric performance of DSSC [14-16]. However, few studies focus on natural NIR dye or cosensitized natural NIR dye.

The strategy for improving the structure and composition of $\mathrm{TiO}_{2}$ electrodes is an additional effective approach to enhance the performance of DSSC, such as a double-layer $\mathrm{TiO}_{2}$ film consisting of transparent nanocrystalline and microcrystalline light-scattering anatase particles was used for photocurrent enhancement of DSSC [17]. Mohammadpour and Janfaza coated nanofibrous as the scattering layer on the $\mathrm{TiO}_{2}$ film, enhancing photocurrent by $11 \%$ [18]. These results showed that scattering double-layer electrodes exhibited a power performance. Novel structure, such as $\mathrm{TiO}_{2}$ nanowires or nanotubes, was also used to enhance the performance of DSSC $[19,20]$.

Diatom frustule could be a promising photoelectric device [21-24]. Previous studies showed that diatom frustule- $\mathrm{TiO}_{2}$ composites as the working electrode could enhance DSSC efficiency. Toster et al. coated frustules with titania nanoparticles to improve the conversion efficiency of DSSC [22]. Huang et al. made diatom frustule- $\mathrm{TiO}_{2}$ composite electrodes with a multilayer structural design, enhancing efficiency by $38 \%$ [23]. In the above studies, sensitizers used in DSSC are N719 synthetic dyes. It remains unclear whether the diatom frustules could improve photoelectric performance of $\mathrm{TiO}_{2}$ electrodes sensitized by natural dyes or other dyes.

Our previous study showed that pigment extracts from purple bacteria exhibited the maximal absorption at $\sim 770 \mathrm{~nm}$ (bacteriochlorophyll $a$ ) in the NIR region and at $400 \sim 550 \mathrm{~nm}$ in the visible region, and diatom pigment extract exhibited the maximal absorption at $\sim 660 \mathrm{~nm}$ (chlorophyll a) $[25,26]$. The aim of this study was to design diatom frustule- $\mathrm{TiO}_{2}$ composite and cosensitize it by two near-infrared spectral complementary natural dyes from purple bacteria and diatom with wide spectrum $(400 \mathrm{~nm} \sim 770 \mathrm{~nm})$ in order to improve the photoelectric conversion efficiency of DSSC. This study showed that pigment extracts from purple bacteria exhibited the characteristic maximal absorption in the NIR region (at $\sim 770 \mathrm{~nm}$, bacteriochlorophyll $a$ ) and in the visible region (at $400 \sim 550 \mathrm{~nm}$ ), and the pigment extract from the diatom exhibited the maximal absorption in the visible region (at $\sim 660 \mathrm{~nm}$, chlorophyll $a$ ). The absorption spectra of the three pigment mixtures displayed an expanding absorption region from Vis to NIR $(400 \sim 500 \mathrm{~nm}, \sim 660 \mathrm{~nm}$, and $\sim 770 \mathrm{~nm})$. The aim of this paper was to prepare diatom frustule- $\mathrm{TiO}_{2}$ composite and cosensitize it by two near-infrared spectral complementary natural dyes from purple bacteria and diatom. The results showed that the combination utilization of diatom frustules and cosensitized dyes greatly enhanced the photoelectric performance of visible-NIR responsive DSSC. This work highlighted the trends in using the biomolecular photosensitizers with Vis-NIR absorbance or spectral complementary cosensitization characteristics for the dyesensitized solar cell and also demonstrated that natural pigment extracts from diatom and purple bacteria and diatom frustules have the potential to be used as materials for fabricating low-cost and eco-friendly dye-sensitized solar cells.

\section{Materials and Methods}

2.1. Materials. Diatom NA56 came from Dongguan Minyi Biotechnology Company. Purple bacteria Rhodopseudomonas palustris strain CQV97 was cultured anaerobically in the modified Ormerod medium [26] at $30^{\circ} \mathrm{C}$, $2500 \mathrm{~lx}$

2.2. Extraction of the Pigment and Diatom Frustules. Pigment was extracted from diatom NA56 following the method as described as follows. In brief, $10 \mathrm{~g}$ of wet cells was extracted in $100 \mathrm{~mL}$ of acetone and under ultrasonic treatment (pulse $4 \mathrm{~s}$, stop $6 \mathrm{~s}, 400 \mathrm{~W}, 90$ times) of ice bath for $15 \mathrm{~min}$ in dim light. Extract was fractioned by centrifuging, and the supernatant solvent was dried under nitrogen. The dried extract suspended in ethanol was the pigment extract of NA56. The pigment of purple bacteria CQV97 was extracted with an acetone/methanol mixture $(7: 2, \mathrm{~V} / \mathrm{V})$ as described previously [27]. In brief, $5 \mathrm{~g}$ of wet cells was extracted in $60 \mathrm{~mL}$ of the acetone/methanol mixture and under the conditions similar to those used for diatom. The dried extract suspended in ethanol was the pigment extract of CQV97. Pigment extracts were stored at $-20^{\circ} \mathrm{C}$ under dark conditions.

The extract of frustules was based on Gell's methods [28]. Deal diatoms with hydrogen peroxide (30 wt\%) and hydrochloric acid $\left(2 \mathrm{~mol} \cdot \mathrm{L}^{-1}\right)$ mixture $(\mathrm{V} / \mathrm{V}=1: 1)$ for $72 \mathrm{~h}$ under dark conditions in order to remove carbonates and organic matter. The pellet was rinsed with ethanol two times and widely washed with distilled water to get neutral $\mathrm{pH}$. Diatom frustules were dried for $3 \mathrm{~h}$ at $130^{\circ} \mathrm{C}$.

2.3. Preparation of the $\mathrm{TiO}_{2}$ Film and Diatom Frustule- $-\mathrm{TiO}_{2}$ Film. $\mathrm{A} \mathrm{TiO}_{2}$ colloid was prepared as described previously [29]. Tetrabutyltitanate $(10 \mathrm{~mL})$ was rapidly added to distilled water $(100 \mathrm{~mL})$, and a white precipitate formed immediately. The precipitate was filtered using a glass frit and washed with distilled water. Under vigorous stirring, the filter cake was added to aqueous solution $(150 \mathrm{~mL})$ containing $1 \mathrm{~mL}$ nitric acid and $10 \mathrm{~mL}$ acetic acid at $80^{\circ} \mathrm{C}$ until the slurry became a translucent blue-white liquid. The bluewhite liquid was autoclaved at $200^{\circ} \mathrm{C}$ for $12 \mathrm{~h}$ to form a milky, white slurry. The resultant slurry was concentrated to $25 \%$ of its original volume, and then PEG-20000 $(0.80 \mathrm{~g})$ and a few drops of the Triton X-100 emulsification reagent were added to form a $\mathrm{TiO}_{2}$ colloid, labeled $T_{0}$. The $\mathrm{TiO}_{2}$ colloid was coated on the fluorine-doped tin oxide-coated glass plate using a doctor scraping method followed by sintering at $450^{\circ} \mathrm{C}$ for $30 \mathrm{~min}$ in air. $\mathrm{TiO}_{2}$ film was immersed in $50 \mathrm{mM}$ $\mathrm{TiCl}_{4}$ aqueous solution at $70^{\circ} \mathrm{C}$ for $30 \mathrm{~min}$ and sintered at $450^{\circ} \mathrm{C}$ for $30 \mathrm{~min}$ in air again. The film was labeled $T$, and the thickness and area of it were controlled to be about $8 \mu \mathrm{m}$ and $0.1 \mathrm{~cm}^{2}$, respectively.

The procedures used for the diatom frustule- $\mathrm{TiO}_{2}$ colloid were similar to those for the $\mathrm{TiO}_{2}$ colloid. $0.40 \mathrm{~g}, 0.80 \mathrm{~g}$, 
$1.20 \mathrm{~g}, 1.60 \mathrm{~g}$, and $0.80 \mathrm{~g}$ diatom frustules were added to distilled water $(20 \mathrm{~mL})$, respectively, and sonicated for $30 \mathrm{~min}$. Subsequently, tetrabutyltitanate $(2 \mathrm{~mL})$ was rapidly added (except for the fifth group) to distilled water containing diatom frustules, respectively, and followed procedures were the same with preparation of $\mathrm{TiO}_{2}$ colloid. The colloids were labeled $F_{1}, F_{2}, F_{3}, F_{4}$, and $F_{0}$ in turn. Then, $T_{0}$ (without diatom frustules), $F_{1}, F_{2}, F_{3}, F_{4}$, and $F_{0}$ (without $\mathrm{TiO}_{2}$ ) colloids were individually coated on the $T$ film. After sintering at $450^{\circ} \mathrm{C}$ for $30 \mathrm{~min}$ in air, double-layer films were obtained and labeled TT (cosensitization double $\mathrm{TiO}_{2}$ film), $\mathrm{TF} 1$ (diatom frustule- $\mathrm{TiO}_{2}(4: 5)$ composite film), TF2 (diatom frustule- $\mathrm{TiO}_{2}(8: 5)$ composite film), TF3 (diatom frustule- $\mathrm{TiO}_{2}$ (12:5) composite film), TF4 (diatom frustule$\mathrm{TiO}_{2}$ (6:5) composite film), and TF0 (diatom frustules without the $\mathrm{TiO}_{2}$ film) in sequence.

\subsection{Dye-Sensitized $\mathrm{TiO}_{2}$ Film and Diatom Frustule-TiO $\mathrm{O}_{2}$ Film}

2.4.1. Different Concentrations of the Pigment Extract-Sensitized $\mathrm{TiO}_{2}$ Film. The concentration of NA56 or CQV97 pigment extracts was determined by the amount of Chl $a$ or BChl $a$, respectively. The single $\mathrm{TiO}_{2}$ layer films $(T)$ were placed in five concentrations of NA56 (with Chl $a$ concentration of $19,38,155,310$, and $620 \mu \mathrm{g} \cdot \mathrm{mL}^{-1}$ ) and CQV97 (with BChl a concentration of 9, 36, 144, 288, and $576 \mu \mathrm{g} \cdot \mathrm{mL}^{-1}$ ) pigment extracts at $4^{\circ} \mathrm{C}$ for $24 \mathrm{~h}$, respectively.

2.4.2. Cosensitization. The T films cosensitized by NA56 and CQV97 pigment extracts were prepared following two methods. (i) The cocktail process, in which the $\mathrm{T}$ films were immersed into the mixture of NA56 and CQV97 pigment extracts $\left(\mathrm{V} / \mathrm{V}, 1: 1\right.$, at the concentration optimized) at $4^{\circ} \mathrm{C}$ for $24 \mathrm{~h}$. (ii) The step-by-step process, in which the T films were first immersed in the NA56 pigment extract for $0 \mathrm{~h}, 2 \mathrm{~h}$, $6 \mathrm{~h}, 12 \mathrm{~h}, 18 \mathrm{~h}, 22 \mathrm{~h}$, and $24 \mathrm{~h}$, respectively, and subsequently transferred into the CQV97 pigment extract and incubated for $24 \mathrm{~h}, 22 \mathrm{~h}, 18 \mathrm{~h}, 12 \mathrm{~h}, 6 \mathrm{~h}, 2 \mathrm{~h}$, and $0 \mathrm{~h}$ in sequence.

2.4.3. Diatom Frustule-TiO $\mathrm{O}_{2}$ Film Sensitized by the NA56 Pigment Extract. The TT, TF1, TF2, TF3, TF4, and TF0 films were immersed in the NA56 pigment extract at $4^{\circ} \mathrm{C}$ for $24 \mathrm{~h}$. TF3 with a better photoelectric performance and its thickness were next optimized. Different amounts of the $F_{3}$ colloid were coated on the $T$ film $(8 \mu \mathrm{m})$ and sintered at $450^{\circ} \mathrm{C}$ for $30 \mathrm{~min}$, and TF3 films were controlled with the thickness of $12 \mu \mathrm{m}, 14 \mu \mathrm{m}, 16 \mu \mathrm{m}$, and $18 \mu \mathrm{m}$, respectively. Subsequently, they were immersed in NA56 pigment extracts at $4^{\circ} \mathrm{C}$ for $24 \mathrm{~h}$.

2.4.4. Diatom Frustule- $\mathrm{TiO}_{2}$ Film Sensitized by Different Dyes. The TF3 Films were immersed in NA56 pigment extracts, CQV97 pigment extracts, cosensitizers (NA56 and CQV97 pigment extracts), and N719 (unique dye of DSSC based on diatom frustules reported previously) at $4^{\circ} \mathrm{C}$ for $24 \mathrm{~h}$.
2.5. Fabrication of DSSC. The pigment-sensitized $\mathrm{T}$ and $\mathrm{TF}$ electrodes and Pt counter electrode were clipped together, and cyanoacrylate adhesive was used as sealant. The composition of the electrolyte was $0.1 \mathrm{M} \mathrm{I}_{2}, 0.1 \mathrm{M} \mathrm{LiI}, 0.6 \mathrm{M}$ tetrabutylammonium iodide, and $0.5 \mathrm{M}$ 4-tertbutylpyridine in acetonitrile.

2.6. Characterization and Measurement. The absorption spectra of pigment extracts and dye-sensitized electrodes were recorded from 300 to $900 \mathrm{~nm}$ using the UV-3200PCS spectrophotometer. The morphologies of diatom frustules and diatom frustule- $\mathrm{TiO}_{2}$ composites were observed by a field emission scanning electron microscope (FESEM) (S4800, HITACHI).

The photoelectric test of DSSC was performed by measuring photocurrent-photovoltage (I-V) characteristic curves at room temperature, white light of $100 \mathrm{~mW} \cdot \mathrm{cm}^{-2} \cdot \mathrm{t}$ (AM1.5) irradiated from a solar simulator, and a CHI660D electrochemical measurement system. According to the I-V curves, the relevant parameters were measured, and the efficiency was calculated. The filling factor (FF) and conversion efficiency $(\eta)$ of DSSC were calculated from the I-V curve, and equation $\mathrm{FF}=\mathrm{P}_{\text {opt }} /\left(I_{\mathrm{sc}} \times V_{\mathrm{oc}}\right)=\left(I_{\text {opt }} \times V_{\text {opt }}\right) /$ $\left(I_{\text {sc }} \times V_{\text {oc }}\right), \quad \eta=P_{\text {opt }} / P_{\text {in }}=\left(\mathrm{FF} \times I_{\text {sc }} \times V_{\text {oc }}\right) / P_{\text {in }}$. In the above equation, $I_{\mathrm{sc}}$ represents the short-circuit current, $I_{\mathrm{opt}}$ represents the optimal photocurrent, $V_{\mathrm{oc}}$ represents the opencircuit voltage, $V_{\text {opt }}$ represents the optimal photovoltage, $P_{\text {opt }}$ represents the optimal output power of the battery, and $P_{\text {in }}$ represents the sunlight input power.

\section{Results and Discussion}

3.1. Characterization of Pigment Extracts. Figure 1(a) shows the absorption spectra of NA56 and CQV97 pigment extracts dissolved in ethanol. NA56 pigment extract mainly consisting of $\mathrm{Ch} a$ and Car exhibits absorption peaks in the visible region at approximately $410 \mathrm{~nm}(\mathrm{Ch} a), 666 \mathrm{~nm}(\mathrm{Ch} a)$, and $450 \mathrm{~nm}$ (Car). CQV97 pigment extract mainly consisting of BCh $a$ and Car shows absorption peaks in the UV-NIR region at approximately $368 \mathrm{~nm}(\mathrm{BCh} a), 598 \mathrm{~nm}(\mathrm{BCh} a)$, $774 \mathrm{~nm}(\mathrm{BCh} a)$, and $475 \mathrm{~nm}$ (Car). Cosensitizer of NA56 and CQV97 pigment extracts exhibits a wider spectral response range than the individual pigment extract.

Figure 1(b) shows the absorption spectra of pigments adsorbed on the $\mathrm{TiO}_{2}$ film. Compared with Figure 1(a), the characteristic absorption peaks in Figure 1(b) were redshifted. The absorption spectra of the cosensitizer on the $\mathrm{TiO}_{2}$ film were expanded within the Vis to NIR region and displayed both characteristic absorption peaks of the pigment extract from NA56 and CQV97. This might be an important reasonable reason for improving photoelectric properties of the cosensitizer on the $\mathrm{TiO}_{2}$ film.

3.2. The Photoelectric Performance of Different Concentrations of the Pigment Extract-Sensitized $\mathrm{TiO}_{2}$ Film. As shown in Figures 2(a) and 2(b), $\eta$ and $I_{\mathrm{sc}}$ increase from 19 to $155 \mu \mathrm{g} \cdot \mathrm{mL}^{-1}$ of Chl $a$ and 9 to $144 \mu \mathrm{g} \cdot \mathrm{mL}^{-1}$ of BChl $a$, respectively, but decrease with further increase in 


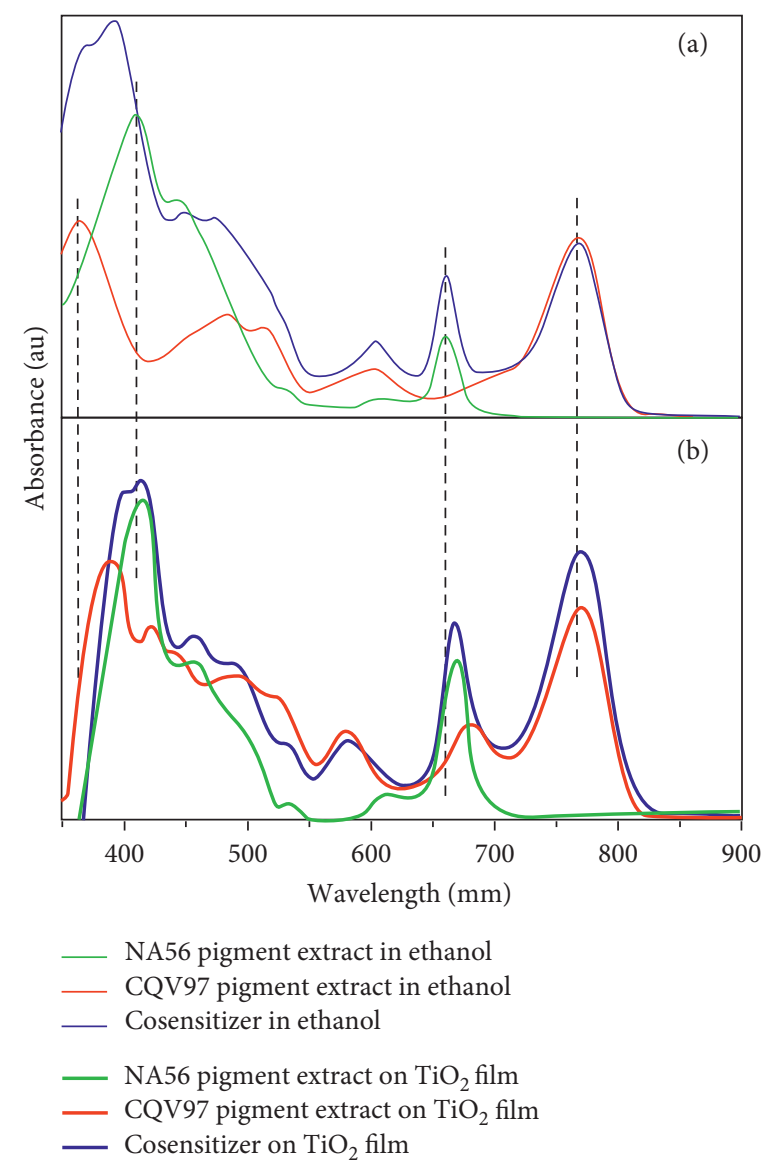

FIGURE 1: UV-Vis absorption spectra of NA56 and CQV97 pigment extracts, and the cosensitizer of them in ethanol (a) and on the TiO film $^{2}$ (b).

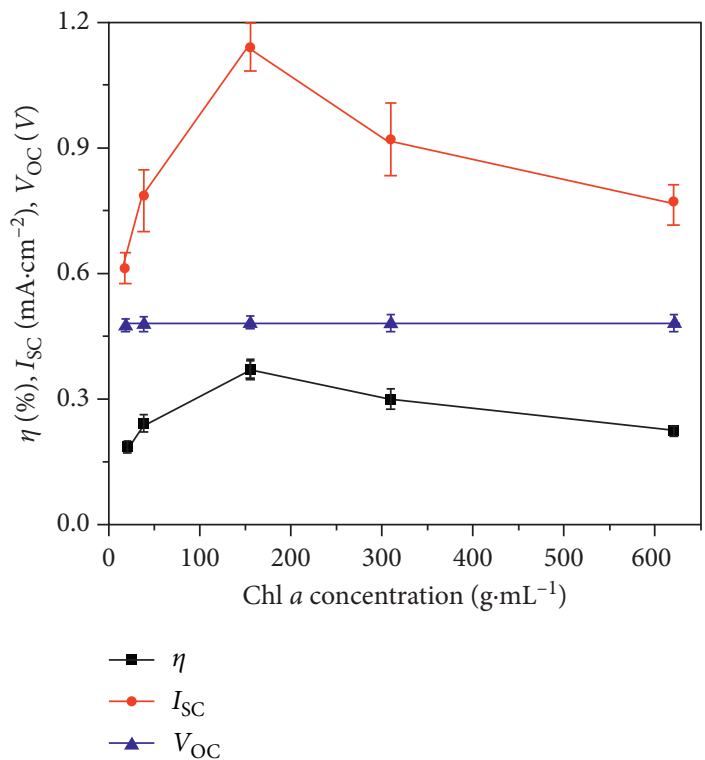

(a)

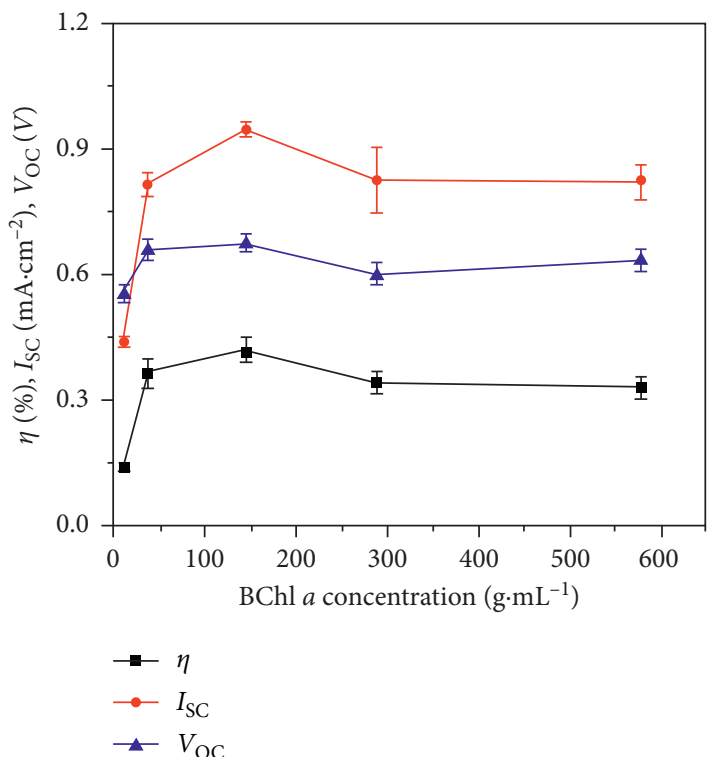

(b)

FIgURE 2: Photoelectric parameters of different concentrations of NA56 (a) and CQV97 (b) pigment extract-sensitized solar cells (standard deviation is the calculate values based on the measurements of three parallel solar cells). 
concentration. Dye in the film will build up with increasing concentration, and an increase in $\eta$ and $I_{\mathrm{sc}}$ would be expected. Dye aggregation, however, becomes more serious in higher concentration, which may lead to intermolecular quenching of photo-excited states or molecules residing in the system that are not functionally attached to the $\mathrm{TiO}_{2}$ surface, causing the decrease of $\eta$ and $I_{\mathrm{sc}}$ [30]. And $V_{\mathrm{oc}}$ fluctuates slightly with the change of concentration. The highest $\eta$ and $I_{\mathrm{sc}}$ values of NA56 and CQV97 pigment extracts are $0.368 \%, \quad 1.139 \mathrm{~mA} \cdot \mathrm{cm}^{-2}$ and $0.417 \%$, $0.950 \mathrm{~mA} \cdot \mathrm{cm}^{-2}$ at the concentration $155 \mu \mathrm{g} \cdot \mathrm{mL}^{-1}$ (Chl a) and $144 \mu \mathrm{g} \cdot \mathrm{mL}^{-1}$ (BChl $\left.a\right)$, respectively.

\subsection{Cosensitization of NA56 and CQV97 Pigment Extracts.} The photovoltaic parameters of the cosensitizer sensitized by the $T$ film are shown in Table 1. A slight increment of conversion efficiency $(0.432 \%)$ is observed in the pigment extract mixture-cosensitized DSSC compared to individual pigment extract-sensitized DSSC $(0.420 \%, 0.372 \%)$.

Remarkably, the photoelectric performance is greatly enhanced by the cosensitization through stepwise procedure. The maximum values of $\eta$ and $I_{\mathrm{sc}}$ reach up to $0.795 \%$ and $1.913 \mathrm{~mA} \cdot \mathrm{cm}^{-2}$ when T films are immersed in the NA56 pigment extract for $12 \mathrm{~h}$ and then in the CQV97 pigment extract for $12 \mathrm{~h}$. $\eta$ exceeds NA56 and CQV97 extract-sensitized DSSC $(0.372 \%, 0.420 \%)$ by $114 \%$ and $89 \%$, respectively. Such increase is possibly attributed to higher lightharvesting capacities of the cosensitizer, which is in agreement with the UV-Vis spectra (see Figure 1) of individual pigment extracts and cosensitizer. After absorption on the $\mathrm{TiO}_{2}$ film, both individual pigment extracts and cosensitizer show characteristic absorption spectra with redshift when compared to their absorption spectrum of dye solution, and cosensitizer demonstrates absorption bands in the visible region at $\sim 400 \mathrm{~nm}$ and $\sim 670 \mathrm{~nm}$ and the NIR region at $\sim 770 \mathrm{~nm}$, with a highly broadened spectral response range. Furthermore, cosensitizer exhibits a great potential to enhance light-harvesting capacities if compared to individual dyes. As shown in Table 1, DSSC cosensitized by stepwise procedure are more efficient than the mixturesensitized DSSC. When NA56 and CQV97 extracts are mixed, unfavorable intermolecular interaction such as dye aggregation could occur which restricts the utilization of original properties of individual dyes for efficient photoenergy conversion process [31]. Stepwise cosensitization could retard the charge recombination and decrease aggregation of the dye absorbed on the $\mathrm{TiO}_{2}$ film to further improve the device performance [32].

\subsection{The Photoelectric Performance of the NA56 Pigment Ex-} tract-Sensitized Diatom Frustule- $\mathrm{TiO}_{2}$ Film. As shown in Table 2, DSSC with the double-layer film are more efficient (except for TF0) than the single layer. The conversion efficiency of the NA56 pigment extract-sensitized TT, TF1, TF2, TF3, and TF4 film is $0.520 \%, 0.641 \%, 0.706 \%, 0.719 \%$, and $0.522 \%$ in sequence, exceeding that sensitized $T$ film by $41 \%, 74 \%, 92 \%, 95 \%$, and $42 \%$, respectively. The photocurrent of DSSC firstly increases and then decreases with the increasing diatom frustules mass ratio of the second layer (Figure 3); a similar trend is seen in their conversion efficiency. However, under the same conditions, $V_{\mathrm{oc}}$ slightly changes. The maximum values of $\eta$ and $I_{\mathrm{sc}}$ reach up to $0.719 \%$ (exceeding $T$ and TT films by $95 \%$ and $38 \%$ ) and $2.006 \mathrm{~mA} \cdot \mathrm{cm}^{-2}$ (exceeding Tand TT films by $76 \%$ and $41 \%$ ) when the mass ratio of diatom frustules $/ \mathrm{TiO}_{2}$ of the second layer is 12:5 (TF3 film). The improvement for the cell incorporating diatom frustules is possibly attributed to enhanced light scattering and trapping. When light strikes diatom frustules, the pores cause multiple reflections thereby increasing the probability for photons to be absorbed by the dye and promoting injection into the semiconductor $[22,23]$. As shown in Figure 4, after the NA56 pigment extract is absorbed on $\mathrm{TiO}_{2}$ and frustule- $\mathrm{TiO}_{2}$ film, both of them show absorption spectra with redshift as compared to that of dye solution. And the spectral response range on the frustule- $-\mathrm{TiO}_{2}$ film is wider than that on the $\mathrm{TiO}_{2}$ film, which may be a reason why the diatom frustules incorporated into $\mathrm{TiO}_{2}$ improved the photoelectric performance of DSSC.

Diatom frustules consist of two halves with many small holes on their surface, approximately $5 \mu \mathrm{m}$ in width and $20 \mu \mathrm{m}$ in length (Figure 5(a)). The small holes of the external surface with diameter of approximately $200 \mathrm{~nm}$ (Figure 5(b)) and internal surface of frustules (Figure 5(c)) have a honeycomb structure with smaller holes (with diameter of approximately $50 \mathrm{~nm}$ ). The results above were basically consistent with the previous study [33]. The SEM images (Figures 5(d) and 5(e)) of diatom frustule- $\mathrm{TiO}_{2}$ materials show that $\mathrm{TiO}_{2}$ nanoparticles successfully coated the surface of diatom frustules, and the diameter of $\mathrm{TiO}_{2}$ particles is about $20 \mathrm{~nm}$.

TF3 thickness is optimized by attaching the second layer diatom frustule- $\mathrm{TiO}_{2}$ film thickness (the first layer is $\mathrm{T}$ film with $8 \mu \mathrm{m}$ thickness). The correlation between thickness and photoelectric performance parameters is shown in Figure $6 \eta$ and $I_{\mathrm{sc}}$ increase within the TF3 film thickness range between 12 and $14 \mu \mathrm{m}$ but decrease with further increase in thickness. The charge recombination between electrons injected from the excited dye to the conduction band of $\mathrm{TiO}_{2}$ and the $\mathrm{I} 3$ ions in the electrolyte will, however, become more serious in thicker films, which leads to the decrease of $\eta$ and $I_{\mathrm{sc}}$ [34]. However, decreased $V_{\mathrm{oc}}$ is attributed to the charge recombination and mass transport limitations in the thicker film.

\subsection{The Photoelectric Performance of Different Dye-Sensitized} TT and TF3 Film. The above results show that diatom frustules incorporated into $\mathrm{TiO}_{2}$ enhanced the photoelectric performance of the NA56 pigment extract-sensitized solar cell. Herein, to test whether the frustules can improve photoelectric performance of DSSC sensitized by other dyes, we further investigate the photovoltaic parameters of the CQV97 pigment extract, cosensitizer (NA56 and CQV97 pigment extracts), and N719-sensitized TT and TF3 films. As shown in Table 3, CQV97 pigment extract, cosensitizer (NA56 and CQV97 pigment extracts), and N719-sensitized TF3 films show conversion efficiency of $0.976 \%, 1.321 \%$, and 
TABle 1: Photovoltaic parameters ${ }^{a}$ of cosensitizer sensitized by $T$ film electrodes ( 3 samples in each group).

\begin{tabular}{|c|c|c|c|c|}
\hline Duration of dye loading & $V_{\mathrm{OC}}(\mathrm{V})$ & $I_{\mathrm{SC}}\left(\mathrm{mA} \cdot \mathrm{cm}^{-2}\right)$ & FF & $\eta(\%)$ \\
\hline$(\mathrm{NA56}+\mathrm{CQV97})(24 \mathrm{~h})$ & $0.607 \pm 0.018$ & $1.199 \pm 0.120$ & $0.610 \pm 0.023$ & $0.432 \pm 0.028$ \\
\hline NA56(0 h) + CQV97(24h) & $0.680 \pm 0.006$ & $0.952 \pm 0.020$ & $0.653 \pm 0.054$ & $0.420 \pm 0.030$ \\
\hline NA56(2 h) + CQV97(22 h) & $0.698 \pm 0.005$ & $1.382 \pm 0.022$ & $0.703 \pm 0.034$ & $0.680 \pm 0.048$ \\
\hline NA56(6h)+CQV97(18 h) & $0.627 \pm 0.005$ & $1.694 \pm 0.140$ & $0.613 \pm 0.011$ & $0.655 \pm 0.052$ \\
\hline NA56(12 h) + CQV97(12 h) & $0.654 \pm 0.005$ & $1.913 \pm 0.143$ & $0.639 \pm 0.032$ & $0.795 \pm 0.031$ \\
\hline NA56(18h) + CQV97(6h) & $0.594 \pm 0.013$ & $1.844 \pm 0.140$ & $0.661 \pm 0.011$ & $0.725 \pm 0.070$ \\
\hline NA56(22 h) + CQV97(2h) & $0.548 \pm 0.006$ & $1.603 \pm 0.034$ & $0.684 \pm 0.018$ & $0.600 \pm 0.034$ \\
\hline NA56(24 h) + CQV97(0 h) & $0.484 \pm 0.005$ & $1.140 \pm 0.050$ & $0.670 \pm 0.025$ & $0.372 \pm 0.020$ \\
\hline
\end{tabular}

${ }^{a}$ Cell performance as reported is the average of four devices. $V_{\mathrm{OC}}$ : open-circuit voltage. $I_{\mathrm{SC}}$ : short-circuit current. FF: filling factor of DSSC. $\eta$ : conversion efficiency of DSSC.

TABle 2: Photovoltaic parameters ${ }^{b}$ of NA56 pigment extract-sensitized diatom frustule- $\mathrm{TiO}_{2}$ film electrodes (4 samples in each group).

\begin{tabular}{|c|c|c|c|c|c|}
\hline Sample & Frustules $/ \mathrm{TiO}_{2}$ mass ratio of second layer & $V_{\mathrm{OC}}(\mathrm{V})$ & $I_{\mathrm{SC}}\left(\mathrm{mA} \cdot \mathrm{cm}^{-2}\right)$ & $\mathrm{FF}$ & $\eta(\%)$ \\
\hline $\mathrm{T}$ & $/^{\mathrm{c}}$ & $0.484 \pm 0.007$ & $1.139 \pm 0.055$ & $0.670 \pm 0.023$ & $0.368 \pm 0.021$ \\
\hline TT & $0: 1$ & $0.485 \pm 0.005$ & $1.426 \pm 0.101$ & $0.748 \pm 0.009$ & $0.520 \pm 0.038$ \\
\hline TF1 & $4: 5$ & $0.561 \pm 0.050$ & $1.670 \pm 0.121$ & $0.695 \pm 0.043$ & $0.641 \pm 0.035$ \\
\hline TF2 & $8: 5$ & $0.578 \pm 0.016$ & $1.789 \pm 0.120$ & $0.693 \pm 0.016$ & $0.706 \pm 0.044$ \\
\hline TF3 & $12: 5$ & $0.505 \pm 0.008$ & $2.006 \pm 0.100$ & $0.712 \pm 0.010$ & $0.719 \pm 0.035$ \\
\hline TF4 & $16: 5$ & $0.517 \pm 0.006$ & $1.388 \pm 0.167$ & $0.726 \pm 0.015$ & $0.522 \pm 0.068$ \\
\hline TF0 & $1: 0$ & $0.503 \pm 0.007$ & $0.848 \pm 0.055$ & $0.764 \pm 0.031$ & $0.326 \pm 0.019$ \\
\hline
\end{tabular}

${ }^{b}$ Cell performance as reported is the average of four devices, and ${ }^{c /}$ " represents no second layer. $\mathrm{T}$ : single $\mathrm{TiO}_{2}$ layer film. TT: cosensitization double TiO ${ }_{2}$ film. $\mathrm{TF} 1$ : diatom frustule- $\mathrm{TiO}_{2}(4: 5)$ composite film. TF2: diatom frustule- $\mathrm{TiO}_{2}(8: 5)$ composite film. TF3: diatom frustule- $\mathrm{TiO}_{2}(12: 5)$ composite film. TF4: diatom frustule- $\mathrm{TiO}_{2}(6: 5)$ composite film. TF0: diatom frustules without the $\mathrm{TiO}_{2}$ film. $V_{\mathrm{OC}}$ : open-circuit voltage. I $\mathrm{SC}_{\mathrm{SC}}$ short-circuit current. FF: filling factor of DSSC. $\eta$ : conversion efficiency of DSSC. (4 samples in each group).

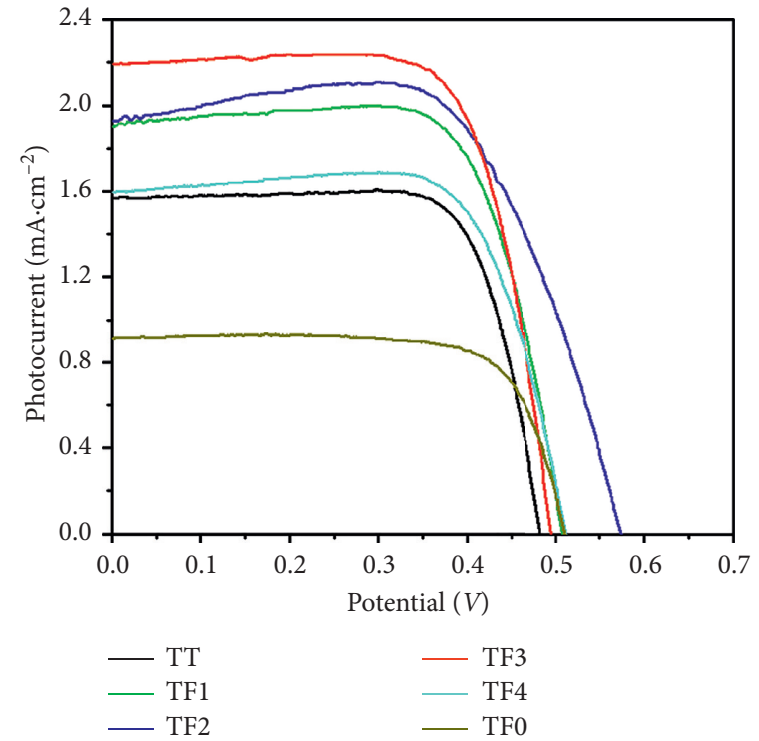

(a)

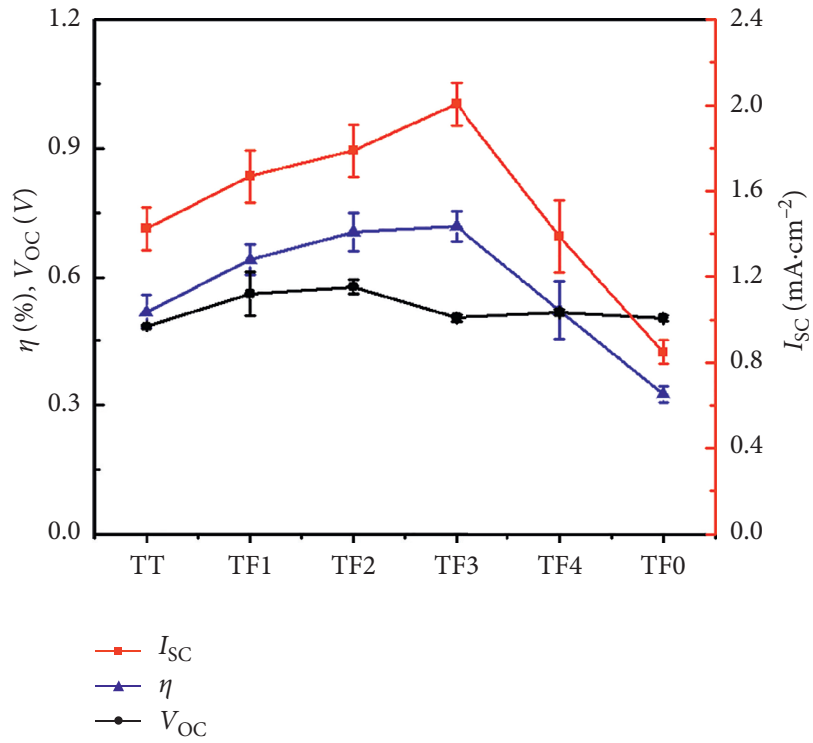

(b)

FIgUre 3: (a) I-V curves and (b) photoelectric parameters of TT, TF1, TF2, TF3, TF4, and TF0 film electrodes (standard deviation is stemmed from Table 2).

$5.844 \%$, enhancing efficiency by $42 \%, 32 \%$, and $34 \%$ compared with that of the sensitized TT film, demonstrating diatom frustule- $\mathrm{TiO}_{2}$ composites made in this work possibly improve photoelectric performance of solar cells sensitized by other dyes. This result was basically consistent with the previous study [23]. The conversion efficiency of cosensitizer (NA56 and CQV97 pigment extracts) sensitized by the TF3 film reaches up to $1.321 \%$, exceeding that $(0.998 \%, 0.520 \%$, and $0.687 \%$ ) of cosensitizer and individual dye-sensitized TT film by $32 \%, 154 \%$, and $92 \%$, respectively; furthermore, it enhances efficiency by $259 \%$ and $217 \%$ when compared with that $(0.368 \%$ and $0.417 \%)$ of the individual dye-sensitized $\mathrm{T}$ film, respectively. It is more efficient than most of the reported chlorophyll- and carotenoid-sensitized solar cells. 


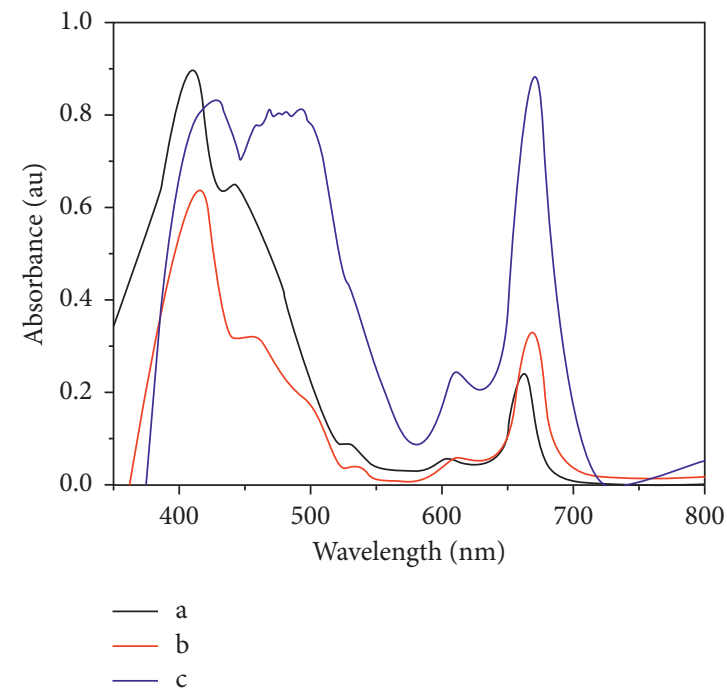

FIGURE 4: UV-Vis absorption spectra of the NA56 pigment extract (a) in ethanol, (b) on $\mathrm{TiO}_{2}$ film, and (c) on diatom frustule- $\mathrm{TiO}_{2}$ (TF3) film.

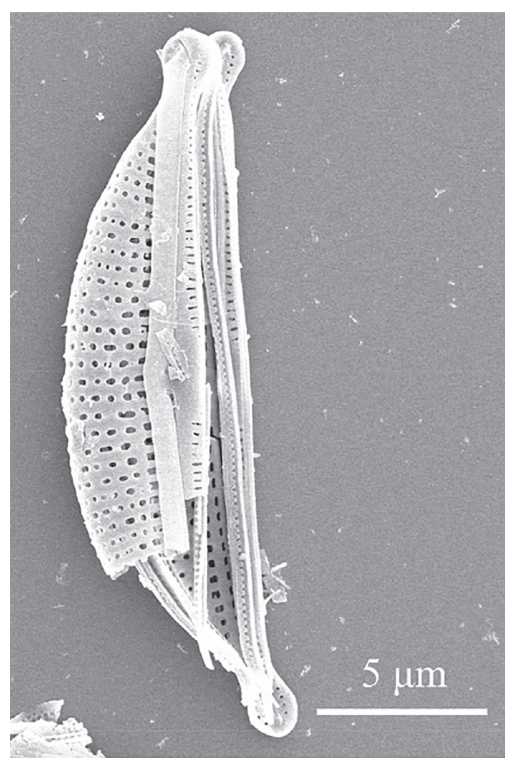

(a)

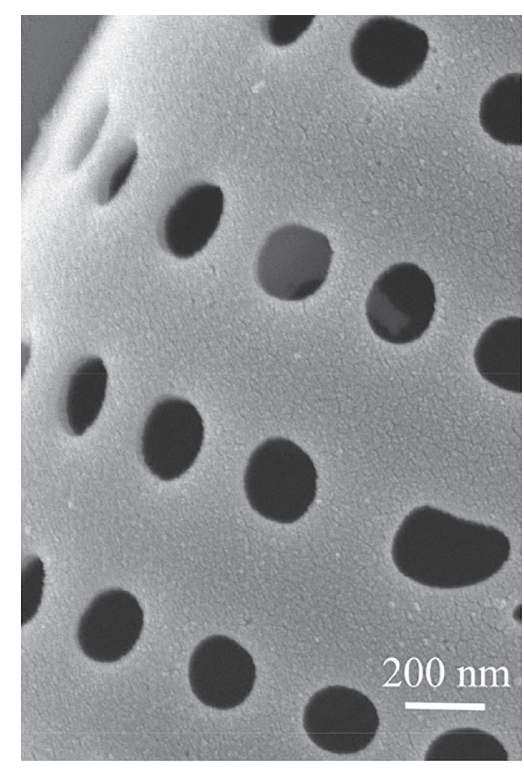

(b)

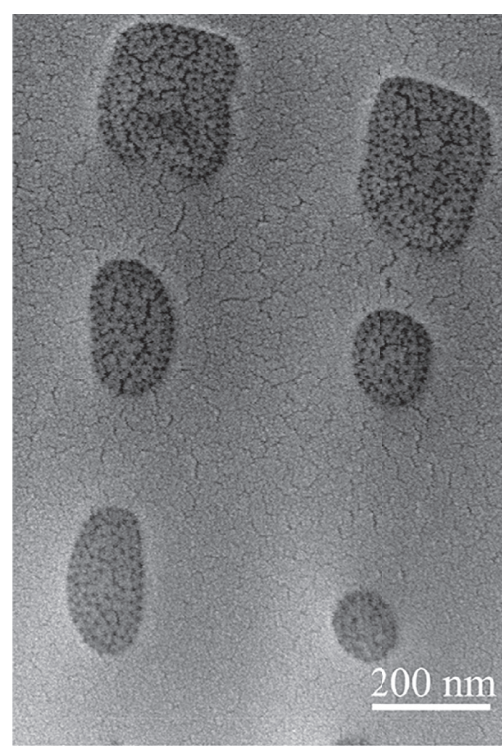

(c)

FIGURE 5: Continued. 


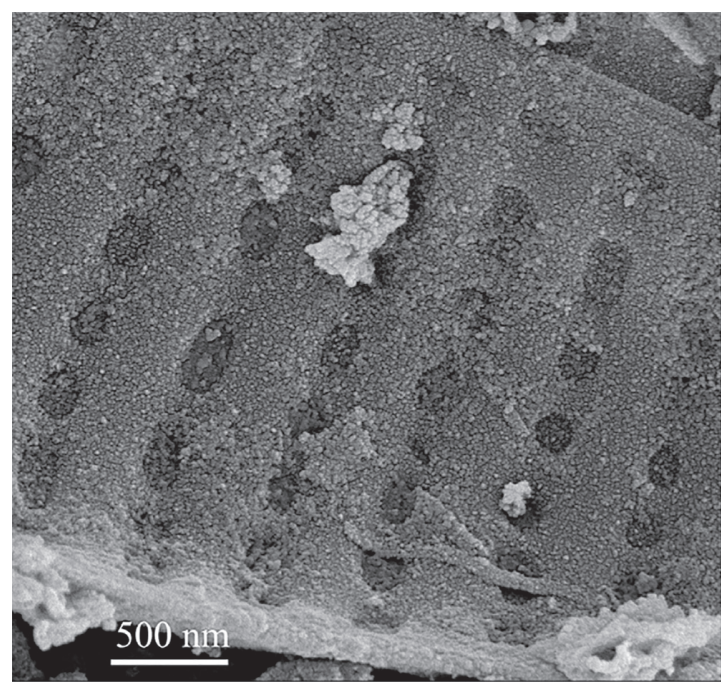

(d)

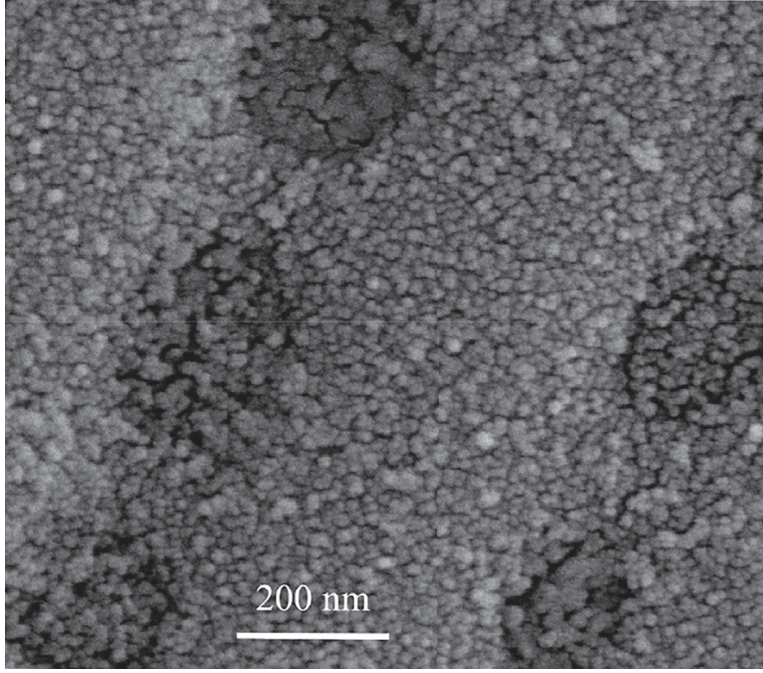

(e)

FiguRE 5: SEM images of (a) diatom frustules, (b) the external surface of diatom frustules, (c) the internal surface of diatom frustules, and (d) and (e) diatom frustule- $\mathrm{TiO}_{2}$.

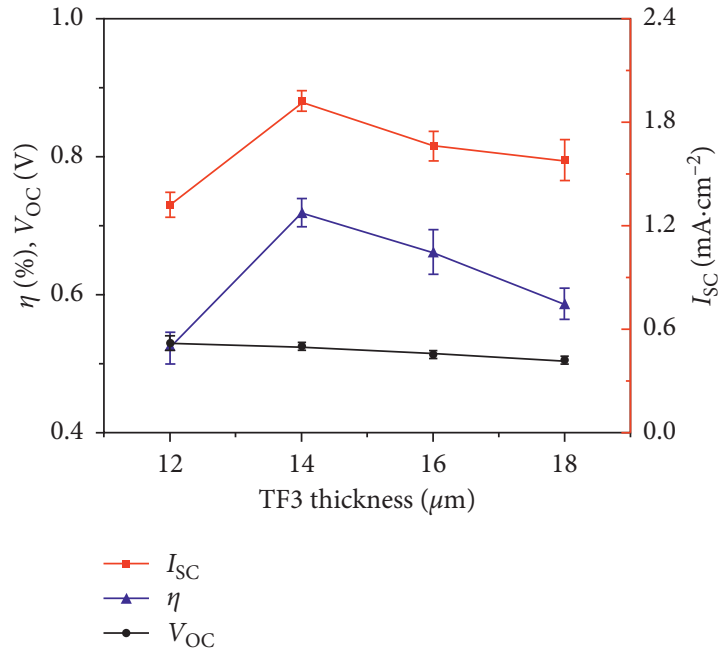

Figure 6: Photoelectric parameters of the TF3 film with different thicknesses (standard deviation is the calculate values based on the measurements of four parallel solar cells).

TABLE 3: Photovoltaic parameters ${ }^{d}$ of dye-sensitized TT and TF3 film electrodes (3 samples in each group).

\begin{tabular}{|c|c|c|c|c|c|}
\hline Film & Dyes & $V_{\mathrm{OC}}(V)$ & $I_{\mathrm{SC}}\left(\mathrm{mA} \cdot \mathrm{cm}^{-2}\right)$ & $\mathrm{FF}$ & $\eta(\%)$ \\
\hline TT & CQV97 pigment extract & $0.685 \pm 0.035$ & $1.330 \pm 0.197$ & $0.752 \pm 0.035$ & $0.687 \pm 0.032$ \\
\hline TT & (NA56 + CQV97) pigment extracts & $0.634 \pm 0.017$ & $2.440 \pm 0.122$ & $0.645 \pm 0.016$ & $0.998 \pm 0.042$ \\
\hline TT & N719 & $0.790 \pm 0.020$ & $7.568 \pm 0.218$ & $0.703 \pm 0.024$ & $4.368 \pm 0.129$ \\
\hline TF3 & CQV97 pigment extracts & $0.736 \pm 0.026$ & $1.621 \pm 0.321$ & $0.774 \pm 0.020$ & $0.976 \pm 0.022$ \\
\hline TF3 & (NA5 + CQV97) pigment extracts & $0.664 \pm 0.024$ & $3.122 \pm 0.150$ & $0.635 \pm 0.019$ & $1.321 \pm 0.096$ \\
\hline TF3 & N719 & $0.793 \pm 0.016$ & $10.740 \pm 0.516$ & $0.674 \pm 0.033$ & $5.844 \pm 0.126$ \\
\hline
\end{tabular}

${ }^{d}$ Cell performance as reported is the average of four devices. TT: cosensitization double $\mathrm{TiO}_{2}$ film. TF3: diatom frustule- $\mathrm{TiO}_{2}$ composite (12:5) film. $V_{\mathrm{OC}}$ : open-circuit voltage. $I_{\mathrm{SC}}$ : short-circuit current. FF: filling factor of DSSC. $\eta$ : conversion efficiency of DSSC. 
Our results further demonstrated that combining cosensitizer with $\mathrm{TiO}_{2}$ electrode incorporating diatom frustules greatly improved the photoelectric performance of DSSC.

\section{Conclusion}

In conclusion, our results showed that cosensitizer- (NA56 and CQV97 pigment extracts-) sensitized $\mathrm{TiO}_{2}$ film exhibited absorption bands in the visible region at $\sim 400 \mathrm{~nm}$ and $\sim 670 \mathrm{~nm}$ and the NIR region at $\sim 770 \mathrm{~nm}$, expanding absorption spectra of individual dyes and yielding conversion efficiency of $0.795 \%$, exceeding that of NA56 and CQV97 pigment extract-sensitized $\mathrm{TiO}_{2}$ film by $114 \%$ and $90 \%$, respectively. The NA56 pigment extract, CQV97 pigment extract, cosensitizer, and N719-sensitized solar cells incorporating diatom frustules (TF3 films) enhanced efficiency by $38 \%, 42 \%, 32 \%$, and $34 \%$ compared with that of sensitized TT films, respectively. The conversion efficiency was further promoted (up to $1.321 \%$ ) when a cosensitizersensitized TF3 film was created. It was more efficient than most of the available chlorophyll- and carotenoid-sensitized solar cells. Pigments of diatom and purple bacteria are easily extracted and eco-friendly. Diatom frustule is a structure designed by nature with the ability of trapping and scattering light. Apparently, the above results show that natural pigment extracts of diatom and purple bacteria and diatom frustules have the potential to be used as materials for fabricating low-cost and eco-friendly dye-sensitized solar cells.

\section{Data Availability}

The data used to support the findings of this study are enclosed within the article. Additional data are accessible from the corresponding author upon request.

\section{Conflicts of Interest}

The authors declare that there are no conflicts of interest regarding the publication of this paper.

\section{Acknowledgments}

The authors acknowledge the financial support by the $\mathrm{Na}$ tional Natural Science Foundation of China (no. 31270106), National Marine Public Industry Research (no. 201505026), the Natural Science Foundation of Fujian Province (no. 2018J0149), and Subsidized Project for Cultivating Postgraduates' Innovative Ability in Scientific Research of Huaqiao University.

\section{References}

[1] M. Hosseinnezhad, M. Ghahari, H. Shaki, and J. Movahedi, "Investigation of DSSCs performance: the effect of 1,8naphthalimide dyes and $\mathrm{Na}$-doped $\mathrm{TiO}_{2}$," Progress in Color, Colorants and Coatings, vol. 13, pp. 177-185, 2020.

[2] Z. Parsa, P. Tahay, and N. Safari, "Co-sensitization of porphyrin and metal-free dye for panchromatic dye-sensitized solar cells," Journal of the Iranian Chemical Society, vol. 17, no. 2, pp. 453-459, 2020.

[3] T. Y. Kim, N. J. Jeon, H. Y. Jung, J. H. Kim, and S. Y. Cho, "Adsorption and photovoltaic properties of lac-color on $\mathrm{TiO}_{2}$ for dye-sensitized solar cells," Journal of Nanoscience and Nanotechnology, vol. 20, pp. 1989-1992, 2020.

[4] M. Raïssi, Y. Pellegrin, F.-X. Lefevre et al., "Digital printing of efficient dye-sensitized solar cells (DSSCs)," Solar Energy, vol. 199, pp. 92-99, 2020.

[5] S. Mathew, A. Yella, P. Gao et al., "Dye-sensitized solar cells with $13 \%$ efficiency achieved through the molecular engineering of porphyrin sensitizers," Nature Chemistry, vol. 6, no. 3, pp. 242-247, 2014.

[6] F. Sauvage, J.-D. Decoppet, M. Zhang et al., "Effect of sensitizer adsorption temperature on the performance of dyesensitized solar cells," Journal of the American Chemical Society, vol. 133, no. 24, pp. 9304-9310, 2011.

[7] A. Yella, H.-W. Lee, H. N. Tsao et al., "Porphyrin-sensitized solar cells with cobalt (II/III)-based redox electrolyte exceed 12 percent efficiency," Science, vol. 334, no. 6056, pp. 629-634, 2011.

[8] G. Calogero, A. Bartolotta, G. D. Marco, A. D. Carlo, and F. Bonaccorso, "Cheminform abstract: vegetable-based dyesensitized solar cells," Chemical Society Reviews, vol. 46, no. 29, pp. 3244-3294, 2015.

[9] H. A. Maddah, V. Berry, and S. K. Behura, "Biomolecular photosensitizers for dye-sensitized solar cells: recent developments and critical insights," Renewable and Sustainable Energy Reviews, vol. 121, Article ID 109678, 2020.

[10] M. Shahid, S. Shahid-Ul-Islam, and F. Mohammad, "Recent advancements in natural dye applications: a review," Journal of Cleaner Production, vol. 53, pp. 310-331, 2013.

[11] B. Basheer, D. Mathew, B. K. George, and C. P. R. Nair, "An overview on the spectrum of sensitizers: the heart of dye sensitized solar cells," Solar Energy, vol. 108, pp. 479-507, 2014.

[12] T. Funaki, H. Funakoshi, O. Kitao et al., "Cyclometalated ruthenium (II) complexes as near-IR sensitizers for high efficiency dye-sensitized solar cells," Angewandte Chemie, vol. 124, no. 30, pp. 7646-7649, 2012.

[13] L.-K. Tsui, J. Huang, M. Sabat, and G. Zangari, "Visible light sensitization of $\mathrm{TiO} 2$ nanotubes by bacteriochlorophyll-C dyes for photoelectrochemical solar cells," ACS Sustainable Chemistry \& Engineering, vol. 2, no. 9, pp. 2097-2101, 2014.

[14] S. Gao, R. Q. Fan, X. M. Wang et al., "Advanced CdII complexes as high efficiency co-sensitizers for enhanced dyesensitized solar cell performance," Dalton Transactions, vol. 44, no. 41, pp. 18187-18195, 2015.

[15] N. Shibayama, H. Ozawa, M. Abe, Y. Ooyama, and H. Arakawa, "A new cosensitization method using the lewis acid sites of $\mathrm{a} \mathrm{TiO}_{2}$ photoelectrode for dye-sensitized solar cells," Chemical Communications, vol. 50, no. 48, pp. 63986401, 2014.

[16] H.-P. Wu, Z.-W. Ou, T.-Y. Pan et al., "Molecular engineering of cocktail co-sensitization for efficient panchromatic porphyrin-sensitized solar cells," Energy \& Environmental Science, vol. 5, no. 12, pp. 9843-9848, 2012.

[17] A. M. Bakhshayesh, "Light scattering management of dyesensitized solar cells based on double-layered photoanodes aided by uniform $\mathrm{TiO}_{2}$ aggregates," Materials Research Bulletin, vol. 73, pp. 268-275, 2016.

[18] R. Mohammadpour and S. Janfaza, "Efficient nanostructured biophotovoltaic cell based on bacteriorhodopsin as biophotosensitizer," ACS Sustainable Chemistry \& Engineering, vol. 3, no. 5, pp. 809-813, 2015. 
[19] G. K. Mor, K. Shankar, M. Paulose, O. K. Varghese, and C. A. Grimes, "Use of highly-ordered $\mathrm{TiO}_{2}$ nanotube arrays in dyesensitized solar cells," Nano Letters, vol. 6, no. 2, pp. 215-218, 2006.

[20] J. Xiao, P. Li, and X. Wen, "Alkali-corrosion synthesis and excellent DSSC performance of novel jujube-like hierarchical $\mathrm{TiO}_{2}$ microspheres," Nanotechnology, vol. 29, no. 17, Article ID 175603, 2018.

[21] R. Gordon, D. Losic, M. A. Tiffany, S. S. Nagy, and F. A. S. Sterrenburg, "The glass menagerie: diatoms for novel applications in nanotechnology," Trends in Biotechnology, vol. 27, no. 2, pp. 116-127, 2009.

[22] J. Toster, K. S. Iyer, W. Xiang, F. Rosei, L. Spiccia, and C. L. Raston, "Diatom frustules as light traps enhance DSSC efficiency," Nanoscale, vol. 5, no. 3, pp. 873-876, 2013.

[23] D.-R. Huang, Y.-J. Jiang, R.-L. Liou, C.-H. Chen, Y.-A. Chen, and C.-H. Tsai, "Enhancing the efficiency of dye-sensitized solar cells by adding diatom frustules into $\mathrm{TiO}_{2}$ working electrodes," Applied Surface Science, vol. 347, pp. 64-72, 2015.

[24] T. M. W. J. Bandara, M. Furlani, I. Albinsson, A. Wulff, and B.-E. Mellander, "Diatom frustules enhancing the efficiency of gel polymer electrolyte based dye-sensitized solar cells with multilayer photoelectrodes," Nanoscale Advances, vol. 2, no. 1, pp. 199-209, 2020.

[25] Q. Fu, C. Zhao, S. Yang, and J. Wu, "The photoelectric performance of dye-sensitized solar cells fabricated by assembling pigment-protein complexes of purple bacteria on nanocrystalline photoelectrode," Materials Letters, vol. 129, pp. 195-197, 2014.

[26] C. Zhao, H. Yue, Q. Cheng, S. Chen, and S. Yang, "What caused the formation of the absorption maximum at $421 \mathrm{nmin}$ Vivospectra of Rhodopseudomonas palustris," Photochemistry and Photobiology, vol. 90, no. 6, pp. 1287-1292, 2014.

[27] M. Q. Zhuo, C. G. Zhao, Q. Cheng, S. P. Yang, and Y. B. Qu, "Fingerprinting analysis of photopigments in purple bacteria," Acta Microbiologica Sinica, vol. 52, no. 6, pp. 760-768, 2012.

[28] P. A. Gell, "The development of a diatom database for inferring lake salinity, western Victoria, Australia: towards a quantitative approach for reconstructing past climates," Australian Journal of Botany, vol. 45, no. 3, pp. 389-423, 1997.

[29] J. Wu, S. Hao, Z. Lan et al., "An all-solid-state dye-sensitized solar cell-based poly ( $\mathrm{N}$-alkyl-4-vinyl-pyridine iodide) electrolyte with efficiency of 5.64\%," Journal of the American Chemical Society, vol. 130, no. 35, pp. 11568-11569, 2008.

[30] S. Ito, H. Miura, S. Uchida et al., "High-conversion-efficiency organic dye-sensitized solar cells with a novel indoline dye," Chemical Communications, vol. 44, no. 41, pp. 5194-5196, 2008.

[31] N. T. R. N. Kumara, P. Ekanayake, A. Lim et al., "Layered cosensitization for enhancement of conversion efficiency of natural dye sensitized solar cells," Journal of Alloys and Compounds, vol. 581, pp. 186-191, 2013.

[32] L. Hui, Y. Z. Wu, Z. Y. Geng, and J. C. Liu, "Co-sensitization of benzoxadiazole based D-A- $\pi$-A featured sensitizers: compensating light-harvesting and retarding charge recombination," Journal of Materials Chemistry A, vol. 2, no. 35, pp. 14649-14657, 2014.

[33] S. Yamanaka, R. Yano, H. Usami, and N. Hayashida, "Optical properties of diatom silica frustule with special reference to blue light," Journal of Applied Physics, vol. 103, no. 7, pp. 074701-074706, 2008.

[34] Z. S. Wang, H. Kawauchi, T. Kashima, and H. Arakawa, "Significant influence of $\mathrm{TiO}_{2}$ photoelectrode morphology on the energy conversion efficiency of N719 dye-sensitized solar cell," Coordination Chemistry Reviews, vol. 248, no. 13-14, pp. 1381-1389, 2004. 